\title{
Pengaruh Penguasaan Matematika Terhadap Prestasi Belajar Siswa Pada Pokok Bahasan Kinematika Gerak
}

\author{
${ }^{1}$ Tsamarul Hizbi, ${ }^{2}$ Badrul Wajdi, ${ }^{3}$ Fartina
}

${ }^{1,2,3}$ Prodi Pendidikan Fisika, MIPA, Universitas Hamzanwadi, Jln. TGKH. M. Zainuddin Abdul Madjid No. 132 Pancor Selong, Lombok Timur, NTB, 83611

Email: tsamarulhizbi@hamzanwadi.ac.id

\begin{tabular}{|c|c|}
\hline Article Info & bstract \\
\hline $\begin{array}{l}\text { Article History } \\
\text { Received: December } 2020 \\
\text { Revised: December } 2020 \\
\text { Published: December } 2020\end{array}$ & \multirow{2}{*}{$\begin{array}{l}\text { This study aims to determine the effect of derivative and integral mastery on } \\
\text { the learning achievement of physics class XI IPA students on motion kinematics } \\
\text { material. The population of this study were all students of class XI IPA at } \\
\text { Madrasah Aliyah NW Kotaraja, amounting to } 36 \text { people. The research method } \\
\text { used is the Ex Post Facto method, by not providing treatment but directly } \\
\text { conducting evaluations related to students 'abilities in motion kinematics } \\
\text { material and also students' abilities related to inherited and integral abilities. } \\
\text { The data analysis technique used is regression analysis. From the results of the } \\
\text { analysis, it is found that Freg-count = } 4.282 \text { and Freg-table = } 4.130 \text { (Freg- } \\
\text { count> Freg-table), the conclusion of this study is that the derivative and } \\
\text { integral mastery affects students' physics learning achievement on the subject } \\
\text { of motion kinematics. }\end{array}$} \\
\hline $\begin{array}{l}\text { Keywords } \\
\text { Derivative mastery, } \\
\text { integrals and kinematics of } \\
\text { motion }\end{array}$ & \\
\hline Info & Abstrak \\
\hline $\begin{array}{l}\text { Sejarah Artikel } \\
\text { Diterima: Desember } 2020 \\
\text { Direvisi: Desember } 2020 \\
\text { Dipublikasi: Desember } 2020\end{array}$ & \multirow{2}{*}{$\begin{array}{l}\text { Penelitian bertujuan untuk mengetahui pengaruh penguasaan turunan dan } \\
\text { integral terhadap prestasi belajar fisika siswa kelas XI IPA pada materi } \\
\text { kinematika gerak, Populasi penelitian ini adalah semua siswa kelas XI IPA di } \\
\text { Madrasah Aliyah NW Kotaraja yang berjumlah } 36 \text { orang. Metode penelitian } \\
\text { yang digunakan adalah dengan metode ex post facto, dengan tidak } \\
\text { memberikan treatment tetapi langsung mengadakan evaluasi terkait } \\
\text { kemampuan siswa pada materi kinematika gerak dan juga kemampuan siswa } \\
\text { terkait kemampuan turunan dan integral. Teknik analisis data yang digunakan } \\
\text { adalah dengan analisis regresi. Dari hasil analisis diperoleh bahwa Freg- } \\
\text { hitung }=4,282 \text { dan Freg-tabel }=4,130 \text { (Freg-hitung > Freg-tabel), maka } \\
\text { kesimpulan penelitian ini adalah penguasan turunan dan integral berpengaruh } \\
\text { terhadap prestasi belajar fisika siswa pokok bahasan kinematika gerak. }\end{array}$} \\
\hline & \\
\hline
\end{tabular}

Sitasi: Hizbi, T., Wajdi. B., \& Fartina, T. (2020). Pengaruh Penguasaan Matematika Terhadap Prestasi Belajar Siswa Pada Pokok Bahasan Kinematika Gerak. Kappa Journal. 4(2), 263-268.

\section{PENDAHULUAN}

Kemampuan siswa dalam memahami materi fisika yang baru sangat dipengaruhi oleh kemampuan dasar. Makin tinggi kemampuan dasar yang dimiliki siswa dalam pelajaran fisika, maka semakin mudah pula untuk menerima pelajaran fisika lanjutan yang diberikan oleh gurunya. Sebaliknya, kurangnya kemampuan dasar yang dimiliki siswa akan menyebabkan sulitnya untuk menerima pelajaran fisika selanjutnya. Oleh karena itu keberhasilan seseorang dalam mempelajari salah satu pokok bahasan fisika sangat dipengaruhi oleh pemahaman dasar yang menjadi materi prasyarat dari materi yang akan dipelajari. Salah satu materi fisika yang membutuhkan pemahaman dasar sebelum mempelajari materi tersebut agar bisa dipahami dengan baik adalah pokok bahasan kinematika gerak. Untuk dapat memahami materi ini siswa seharusnya sudah memiliki 
pemahaman dasar yang terkait dengan konsep kinematika gerak. Salah satu materi yang harus dikuasai adalah materi turunan dan integral fungsi.

Poerwardarminta (1984) mengatakan bahwa penguasaan adalah kemampuan dan kesanggupan orang untuk mengetahui. Ahli lain mengatakan bahwa penguasaan adalah kemampuan atau kesanggupan untuk berbuat sesuatu. Jadi penguasaan dapat diartikan kemampuan atau kesanggupan seseorang untuk berbuat sesuatu. Jadi penguasaan turunan dan integral merupakan pemahaman atau kesanggupan untuk menggunakan kepandaian, kecerdasan, pengetahuan untuk mengetahui atau memahami turunan dan integral.

Sebagaimana yang telah kita ketahui bahwa matematika sangat erat kaitannya dengan ilmu pengetahuan alam, sementara itu salah satu mata pelajaran yang termasuk kedalam ilmu pengetahuan alam adalah fisika, sehingga dikatakan pula matematika sangat erat kaitannya dengan fisika. Kaitan yang dimaksudkan disini salah satunya adalah materi-materi matematika merupakan prasyarat untuk memahami materi-materi fisika. Oleh sebab itu, agar pembelajaran suatu materi dapat terlaksana dengan efektif dan efisien, tentunya harus menguasai materi yang menjadi prasyarat materi tersebut. Misalnya, pada materi kinematika gerak dengan analisis vektor yang didalamnya terdapat hubungan turunan dan integral antara jarak (posisi), laju (kecepatan), dan percepatan. Jika siswa ingin memahami materi tersebut maka terlebih dahulu harus memahami materi matematika pokok bahasan turunan dan integral, karena materi turunan dan integral merupakan materi prasyarat untuk memahami materi kinematika gerak dengan analisis vektor.

Hasil penelitian Sartika Ayu dkk, 2020 menemukan; kurang dikuasainya konsep turunan dan integral oleh para siswa pada matematika sehingga seringkali membuat masalah bagi siswa didalam memahami materi fisika seperti pada pokok bahasan kinematika gerak dengan analisis vektor. Disamping itu juga minat dan bakat merupakan sesuatu yang mempengaruhi prestasi belajar siswa, juga termasuk profesionalisme guru dalam mengajar. Sebagaimana yang dikemukakan oleh para ilmuan bahwa minat dan bakat merupakan faktor yang berasal dari dalam diri individu (internal). Jika minat dan bakat siswa rendah maka kemampuan siswa dalam menerima stimulus akan rendah yang menyebabkan prestasi belajar siswa rendah. Sedangkan untuk profesionalisme guru merupakan faktor yang berasal dari luar diri siswa (eksternal). Profesionalisme guru yang dimaksudkan disini adalah metode-metode yang digunakan oleh guru dalam proses pembelajaran.

Sebagaimana yang kita ketahui bahwa setiap individu berbeda-beda. Oleh sebab itu kemampuan dan cara dalam menerima stimulus juga berbeda-beda. Misalnya dengan mengguanakan metode demonstrasi ada individu yang menerima dengan cepat dan ada juga individu yang menerima dengan lambat atau bahkan ada yang tidak bisa menerima stimulus tersebut.

Dari hasil observasi yang dilakukan di Madrasah Aliyah Nahdlatul Wathan Kotaraja diperoleh; rata-rata hasil ulangan tengah semester ganjil dimana materi kinematika gerak dipelajari, sementara itu pengetahuan siswa tentang turunan dan integral juga variatif dan guru fisika tidak pernah menghubungkan antara matematika yang digunakan pada materi kinematika gerak fisika.

\section{METODE}

Metode penelitian yang digunakan dalam penelitian ini adalah Ex Post Facto. Menurut (Darmadi, 2013) penelitian Ex post facto adalah penelitian di mana variabel-variabel bebas telah terjadi ketika peneliti memulai dengan pengamatan variabel terikat dalam suatu penelitian. Menurut (Baso IS, 2010) penelitian ex-post facto meneliti hubungan sebab-akibat yang tidak dimanipulasi atau tidak diberi perlakuan oleh peneliti. Penelitian sebab-akibat dilakukan terhadap program, kegiatan atau kejadian yang telah berlangsung atau telah terjadi. Adanya hubungan sebab-akibat didasarkan atas kajian teoretis, bahwa sesuatu variabel disebabkan atau dilatarbelakangi oleh variabel tertentu atau mengakibatkan variabel tertentu. 
Hal tersebut yang menjadi alasan peneliti untuk metode memilih metode penelitian ex post facto.

Metode ini dipilih karena peneliti tidak dapat mengontrol variabel bebas melalui manipulasi atau perlakuan secara eksperimen sebab perlakuan telah ada dan telah terjadi sebelumnya oleh orang lain yang bukan peneliti (Sudjana. 2009). Dengan demikian, peneliti tidak mengadakan kegiatan pembelajaran tentang penguasaan turunan dan integral suatu fungsi secara langsung karena kegiatan pembelajaran telah terjadi secara tidak langsung ketika mempelajari kinematika gerak dengan analisis vektor. Hal ini menunjukkan pula bahwa penguasaan atau materi-materi tersebut sudah mereka peroleh secara tidak langsung saat mempelajari kinematika gerak dengan analisis vektor. Oleh sebab itu data penguasaan turunan dan integral suatu fungsi dan pemahaman materi kinematika gerak dengan analisis vektor dapat diperoleh melalui hasil tes yang diberikan oleh peneliti.

Teknik uji yang digunakan untuk menguji hipotesis dalam penelitian ini adalah dengan analisis regresi. Analisis regresi ini digunakan untuk memprediksikan seberapa jauh perubahan nilai variabel dependen bila nilai variabel independen dimanipulasi/dirubah-rubah atau dinaik-turunkan. (Sugiyono, 2008). Persamaan umum regresi linier sederhana adalah:

$Y=a+b X$

Dimana: $Y=$ subjek dalam variabel dependen yang diprediksikan, $a=$ harga harga $Y$ ketika harga $X=0$ (harga konstan), $b=$ angka arah atau koefisien regresi yang menunjukkan angka peningkatan ataupun penurunan variabel dependen yang didasarkan pada perubahan variabel independen. Bila (+) arah garis naik, dan bila (-) maka arah garis turun. $X=$ subjek pada variabel independen yang mempunyai nilai tertentu.

Selanjutnya menghitung nilai F menggunakan rumus:

$F=\frac{S_{\text {reg }}^{2}}{S_{\text {sisa }}^{2}}$

$F$-hitung dibandingkan dengan $F$-tabel dengan dk pembilang $=1$ dan dk penyebut $=n$ 2 menggunakan taraf kesalahan 5\% dengan kriteria $F$-hitung $>F$-tabel. (Sugiyono, 2008). Kemudian ditentukan koefisien korelasi antara kedua variabel menggunakan rumus korelasi product moment angka kasar sebagai berikut:

$$
r_{x y}=\frac{n \Sigma X_{i} Y_{i}-\left(\Sigma X_{i}\right)\left(\Sigma Y_{i}\right)}{\sqrt{\left(n \Sigma X_{i}^{2}-\left(\Sigma X_{i}\right)^{2}\right)\left(n \Sigma Y_{i}^{2}-\left(\Sigma Y_{i}\right)^{2}\right)}}
$$

Selanjutnya ${ }^{x y}$ hitung dibandingkan dengan $r_{x y}$ tabel dengan kriteria $r_{x y}$ hitung $>r_{x y}$ tabel dan tingkat signifikansi 5\%. (Sugiyono, 2008). Selanjutnya untuk menjawab apakah harga $r_{x y}$ signifikan atau tidak, dilakukan analisis regresi (Anareg). Dari pengerjaan anareg ini diperoleh harga $F$ garis regresi yang dilambangkan dengan $F_{\text {reg }}$ yaitu dengan menggunakan persamaan sebagai berikut:

$$
F_{\text {reg }}=\frac{R^{2} / k}{\left(1-R^{2}\right) /(n-k-1)}
$$

Dengan keterangan, $F_{\text {reg }}=$ harga $F$ garis regresi yang dicari, $n=$ banyaknya subjek yang terlibat, $k=$ banyaknya prediktor, $R=$ koefisien korelasi antara kriterium dengan prediktor-prediktor. Dengan kriteria; apabila harga $F_{\text {reg }}>F_{\text {tabel }}$ dengan taraf signifikan 5\% maka data tersebut signifikan. (Sugiyono, 2008).

\section{HASIL DAN PEMBAHASAN}

Hasil test prestasi belajar siswa pada pokok bahasan kinematika gerak dengan analisis vector diperoleh nilai terendah adalah 27 dan nilai tertinggi adalah 77 sementara itu nilai ratarata sebesar 50,5. Berikut data dalam bentuk tabel distribusi: 
Tabel 2. Distribusi Frekuensi Data Hasil Evaluasi Prestasi Belajar Pokok Bahasan Kinematika Gerak Dengan Analisis Vektor.

\begin{tabular}{lll} 
No. & Interval Kelas & Frekuensi \\
\hline 1 & $27-35$ & 2 \\
\hline 2 & $36-44$ & 9 \\
\hline 3 & $45-53$ & 11 \\
\hline 4 & $54-62$ & 6 \\
\hline 5 & $63-71$ & 5 \\
\hline 6 & $72-80$ & 3 \\
\hline Jumlah & & 36
\end{tabular}

Dalam bentuk histogram nampak seperti gambar berikut:

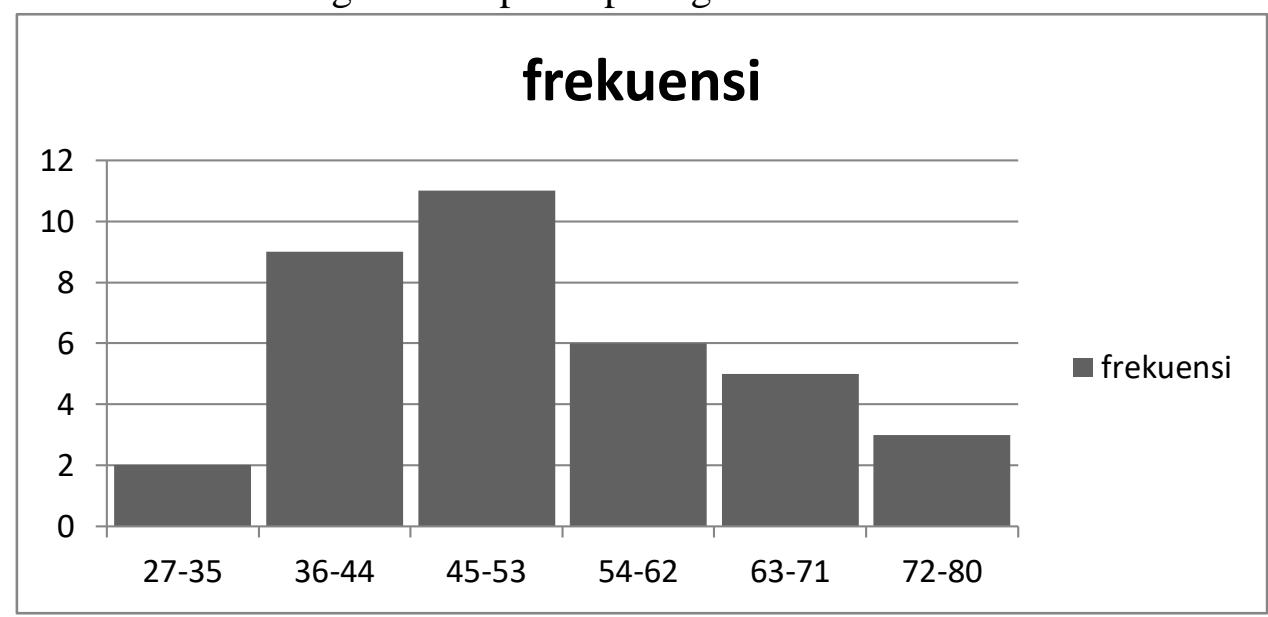

Gambar 1. Prestasi Belajar Fisika Pokok Bahasan Kinematika Gerak Dengan Analisis Vektor.

Sedangkan data kemampuan matematika khususnya turunan dan integral diperoleh data nilai terendah 30, nilai tertinggi 80 dan nilai rata-rata dieroleh 54,06. Berikut data lengkap dalam bentuk tabel distribusi.

Tabel 3. Data Kemampuan Turunan Dan Integral Siswa

\begin{tabular}{lll} 
No & Interval & Frekuensi \\
\hline 1 & $30-38$ & 6 \\
\hline 2 & $39-47$ & 5 \\
\hline 3 & $48-56$ & 8 \\
\hline 4 & $57-65$ & 11 \\
\hline 5 & $66-74$ & 3 \\
\hline 6 & $75-83$ & 3 \\
\hline Jumlah & 36
\end{tabular}


Sementara itu data dalam bentuk histogram terlihat seperti gambar berikut:

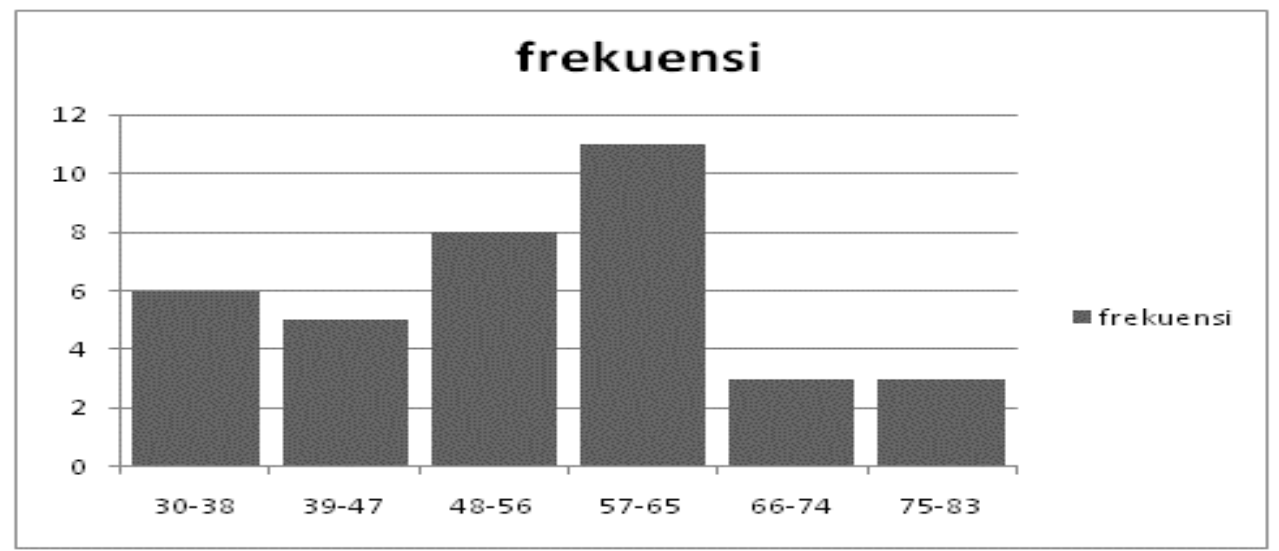

Gambar 2. Kemampuan Turunan dan Integral Siswa

Dari perhitungan uji linearitas didapatkan $F$ hitung $=0,594$ dan $F$ tabel $=2,235(F$ hitung $<F$-tabel). Dengan demikian sesuai dengan kriteria yang telah diajukan maka hasil penelitian adalah linear, dan untuk uji keberartian dimaksudkan untuk mengetahui eratnya hubungan antara penguasaan turunan dan integral dengan prestasi belajar fisika pokok bahasan kinematika gerak dengan analisis vector. Dari perhitungan uji keberartian didapatkan $F$-hitung $=4,28$ dan $F$-tabel $=4,13(F$-hitung $>F$-tabel $)$, Dengan demikian hasil penelitian ini berarti. Selanjutnya untuk mengetahui korelasi antara penguasaan turunan dan integral dengan prestasi belajar fisika pokok bahasan kinematika gerak dengan analisis vector digunakan rumus $r$-product moment $\left(r_{x y}\right)$. Dari perhitungan $r_{x y}$ hitung $=0,334$ dan $r_{x y}$ tabel $=$ 0,329 ( $r_{x y}$ hitung $>r_{x y}$ tabel). Dengan demikian terdapat hubungan yang positif dan signifikan. Dari hasil perhitungan analisis regresi diperoleh Freg-hitung = 4,282 dan Fregtabel $=4,130$ (Freg-hitung > Freg-tabel), maka Ha diterima .

Hasil penelitian ini serupa dengan hasil penelitian yang dilakukan oleh Anggun Ika Pristanti, Amiruddin Hatibe, dan Sahrul Saehana pada tahun ajaran 2016/2017, dengan judul pengaruh kemampuan matematika dan motivasi belajar terhadap kemampuan fisika siswa SMA Negeri 4 Palu. Kesimpulan penelitian ini adalah terdapat hubungan yang signifikan antara kemampuan matematika dan motivasi belajar dengan kemampuan fisika siswa SMA Negeri 4 Palu. Menurut Ika P dkk, siswa yang memiliki kemampuan matematika baik dapat diprediksi memiliki kemampuan dalam memahami konsep fisika dan kemampuan dalam menyesaikan soal-soal perhitungan fisika, sehingga dapat meningkatkan hasil belajar siswa. Tomi Hidayat dan Ira Nofita Sari juga melakukan penelitian serupa dengan judul; Korelasi kemampuan matematis dengan hasil belajar pada materi suhu di kelas X SMA Negeri 1 Jawai Selatan pada tahun 2019. Kesimpulan penelitian ini adalah hubungan antara kemampuan matematis dengan hasil belajar fisika memiliki tingkat hubungan yang kuat di kelas X SMA Negeri 1 Jawai Selatan. Hal menarik yang ditemukan oleh Tomi dan Ira yaitu dia mendapatkan seperti yang dikatakan oleh Tzanaski, menyatakan bahwa matematika dan fisika memiliki hubungan yang erat, hubungan antara keduanya yaitu: (1) metode matematika digunakan dalam fisika dan (2) konsep, pendapat dan cara berfikir fisika digunakan dalam matematika. Sehingga hubungan antara fisika dan matematika tidak boleh diabaikan dalam disiplin ilmu.

Ilmu fisika sangat erat kaitannya dengan ilmu-ilmu yang lain terutama Ilmu Pengetahuan Alam (IPA). Karena fisika adalah merupakan salah satu bagian dari ilmu pengetahuan alam (IPA). Dan yang tidak kalah erat kaitannya dengan ilmu fisika adalah matematika, dimana penguasaan materi-materi matematika sangat dibutuhkan dalam membahas materi-materi fisika. Salah satu materi matematika yang sangat erat kaitannya dengan materi fisika sebagaimana yang dibahas dalam penelitian ini adalah turunan dan 
integral yang erat kaitannya dengan kinematika gerak dengan analisis vektor. Sebagaimana yang diperoleh dalam penelitian ini, yaitu terdapat pengaruh yang positif dan signifikan antara penguasaan turunan dan integral terhadap prestasi belajar fisika siswa pada pokok bahasan kinematika gerak dengan analisis vektor. Artinya bahwa penguasaan turunan dan integral juga menentukan prestasi belajar fisika pada pokok bahasan kinematika gerak dengan analisis vektor disamping faktor-faktor yang lain.

Ungkapan ini menunjukkan bahwa dalam membahas atau mempelajari kinematika gerak dengan analisis vektor akan lebih baik jika terlebih dahulu sudah menguasai turunan dan integral. Hal tersebut dikarenakan oleh didalam pembahasan kinematika gerak dengan analisis vektor terdapat hubungan turunan dan integral antara posisi, jarak, kecepatan, dan percepatan.

\section{KESIMPULAN}

Kesimpulan penelitian ini adalah terdapat pengaruh yang positif dan signifikan antara penguasan turunan dan integral terhadap prestasi belajar fisika siswa pada pokok bahasan kinematika gerak pada siswa kelas XI MA.

\section{SARAN}

Saran dalam penelitian ini adalah: Bagi para pembaca supaya didalam mempelajari kinematika gerak dengan analisis vektor sebaiknya terlebih dahulu menguasai turunan dan integral, Bagi guru-guru fisika hendaknya berkonfirmasi dengan guru-guru matematika sekolah setempat dalam pembuatan perangkat pembelajaran terkait dengan penyusunan silabus agar silabus materi turunan dan integral dalam matematika disusun sebelum silabus materi kinematika gerak fisika.

\section{UCAPAN TERIMA KASIH}

Ucapan terimakasih disampaikan kepada semua pihak yang telah ikut membantu dalam proses penelitian ini.

\section{DAFTAR PUSTAKA}

Ariana, S. A., Mansyur, J., \& Supriyatman, S. Analisis Pemahaman Konsep Siswa Kelas XII SMA Negeri 6 Palu tentang Vektor. Jurnal Kreatif Online, 8(1).

Hamid, D. (2013). Dimensi-Dimensi Metode Penelitian Pendidikan Dan Sosial. Bandung: Alfabeta.

Hidayat, T., \& Sari, I. N. (2019). Korelasi Kemampuan Matematis dengan Hasil Belajar pada Materi Suhu di Kelas X SMA Negeri 1 Jawai Selatan. JURNAL PENDIDIKAN SAINS DAN APLIKASINYA, 2(2), 36-39.

Muhibbin, S. (1999). Psikologi Pendidikan dan Pendekatan Baru. Rosdakarya, Bandung. PT Remaja.

Poerwadarminta, W. J. S. (1984). Kamus Umum Bahasa Indonesia, Jakarta: PN. Balai Pustaka.

Pristanti, Anggun Ika, Amiruddin Hatibe, and Sahrul Saehana. "Pengaruh Kemampuan Matematika dan Motivasi Belajar Terhadap Kemampuan Fisika Siswa SMA Negeri 4 Palu." JPFT (Jurnal Pendidikan Fisika Tadulako Online) 5.3: 37-40.

Sappaile, B. I. (2010). Konsep Penelitian Ex-Post Facto. Jurnal Pendidikan Matematika, 1(2), 1-16.

Sudjana, N. (2009). Penelitian hasil proses belajar mengajar. Bandung: Rosdakarya..

Sugiyono. (2008). Metode penelitian pendidikan:(pendekatan kuantitatif, kualitatif dan $R \&$ D). Alfabeta. 